\title{
Exploratory Analysis of College Students' Satisfaction of Body Scanning with Kinect
}

\author{
Shu-Hwa LIN ${ }^{a}$, Rayneld JOHNSON ${ }^{b}$, Didier STRICKER ${ }^{c}$, Yan CUI ${ }^{c}$ \\ a University of Hawaii at Manoa, Honolulu (HI), USA; \\ ${ }^{b}$ Wayne State University, Detroit (MI), USA; \\ ${ }^{c}$ DFKI, Augmented Vision, Kaiserslautern University, Germany
}

\begin{abstract}
This study explores college students' attitudes toward body scanning and the creation of an avatar using a Kinect operating system. A select sample of 86 female and male college students participated in the study. Using a Windows 7 operating system with Kinect to provide a stable platform for the NUI audio and motor devices, students' bodies were scanned and an avatar was created. Bodies were scanned from 360 degrees to obtain 360 pictures and 360 depth frames (i.e. about 10 degrees between each view). Outputs with PNG and PLY files were abstrated from the scan data and processed into a 3D model reconstruction or avatar by Wissenschaftlicher Mitarbeiter. The program, MeshLab, was used to view and measure the avatar. Following the scanning process, subjects responded to a 20 item questionnaire about the process and resulting avatar. Overall, participants expressed positive reactions to the body scanning process and satisfaction with their avatar and body shape, and provided information about the use of avatars.
\end{abstract}

Keywords: 3d body scanning, image technology. Avatars, Kinect

\section{Introduction}

The use of digital avatars provides a new form of digital body measurements and fit simulation and can be used in marketing applications [1]. Advanced technology is changing the way companies operate in the apparel and soft goods industry. Additionally, body scanning has contributed to accurate body measurements and garment-fitting simulation and has been improving the sizing system for more than a decade. Now accurate body images and measurements are readily available, however, the costs can be prohibitive. Costs could range between US $\$ 200,000$ and US $\$ 20,000$ when a laser or incandescent white light are used for high-end products. Although manufacturers and designers would like to take advantage of features like accurate body measurements and virtual clothing simulation, many apparel companies cannot afford to install such devices due to high cost or insufficient physical space $[2,3,4]$.

Kinect, developed by Microsoft, is an affordable home device that senses motion as input. Kinect employs a revolutionary technique designed for games, entertainment, and fitness (Wii-Fit). It promotes body movement so people can exercise without using a controller or manual touch [1]. In less than three years, Kinect has been adopted in several laboratories to scan human bodies $[5,6]$. Also, some CAD companies have targeted retailers to successfully develop online fitting rooms to use Kinect AutoCAD and TUKA CAD. Additionally, some 3D mirror virtual try-on technologies were developed by IBM and CISCO for retail use. Some on-line stores have used a mirror function to let consumers practice the virtual try-on apparel and fit simulations.

Consumers express readiness to use avatars to try on clothing when the body size of the avatar appears to be close to their own size. The use of body images and the creation of avatars will appeal to stakeholders who want to promote healthy activity, clothing selection, entertainment activities, and the growth of small businesses. Small businesses can adopt virtual fitting rooms for virtual try-on to develop new business strategies and create a border-free business world [7]. Also, researchers suggest that older persons' experiences of body image and leisure have more positive than negative reactions [8].

With limited investment, this research explores developing the body scanning process and use of an avatar. The creative process and method to body scan with Kinect, an affordable home device, can benefit many students and small businesses. Researchers, students, small business designers will understand body scanning, body measurements, size, and fit assessment. The objectives included: a) Developing a creative process and method to body scan with Kinect, b) Understanding the needs of body scanning with Kinect, c) Virtual body measurement and fit assessment, d) Understanding fit simulation (for designers' role) and virtual try-on (for consumers' role), d) Acquiring knowledge of exercises such as free form body movement, and e) Stimulating creativity. 


\section{Method}

\subsection{Participants}

A total of 86 undergraduate and graduate students ranging in age from 18-45 years voluntarily participated in this body scanning project including 78 female and 8 male college students. Subjects were asked to wear their own tight clothing such as: a swim suit or sport bra with tight shorts for females and fitted boxers for males. For each participant, the body scan process was conducted in a private room and took about 15-20 minutes. Female subjects were most likely to accept the attire invitation, however, some male subjects hesitated to accept this invitation and felt uncomfortable for this setting. More than $70 \%$ of the subjects were Asian, $17 \%$ were Caucasian, and $5 \%$ were other ethnic groups.

\subsection{Procedure}

A Windows 7 operating system was used with Kinect to create a stable platform for the NUI audio, camera and motor devices. All body scan software and procedures were provided by Wissenschaftlicher Mitarbeiter. All data from 360 degrees to obtain 360 pictures and 360 depth frames (i.e., 10 degrees between each view) for each subject were collected. An open stance (with feet placed 6 inches apart) marked on legal size paper over the top of a lazy-susan turn table was adopted to rotate subjects 10 degrees between each view. Due to new exploration of the process, researchers tried four scans on the first ten subjects in order to achieve successful procedures. Outputs with PNG and PLY files were abstrated from the scan data and processed into a 3D model reconstruction or avatar by Wissenschaftlicher Mitarbeiter. MeshLab, a free download program, was used to view and measure the avatar. Participants used this body scan image to analyze their body type. Also, avatars can be converted into points, wireframe, hidden lines, flat lines, flat and smooth formats.

\subsubsection{Captures from Kinect}

Kinect was set to capture subjects' body images from 360 degrees about 10 degrees between each view. Ten color and depth frames pictures were captured for each view. A total of 740 files were documented from each subject.

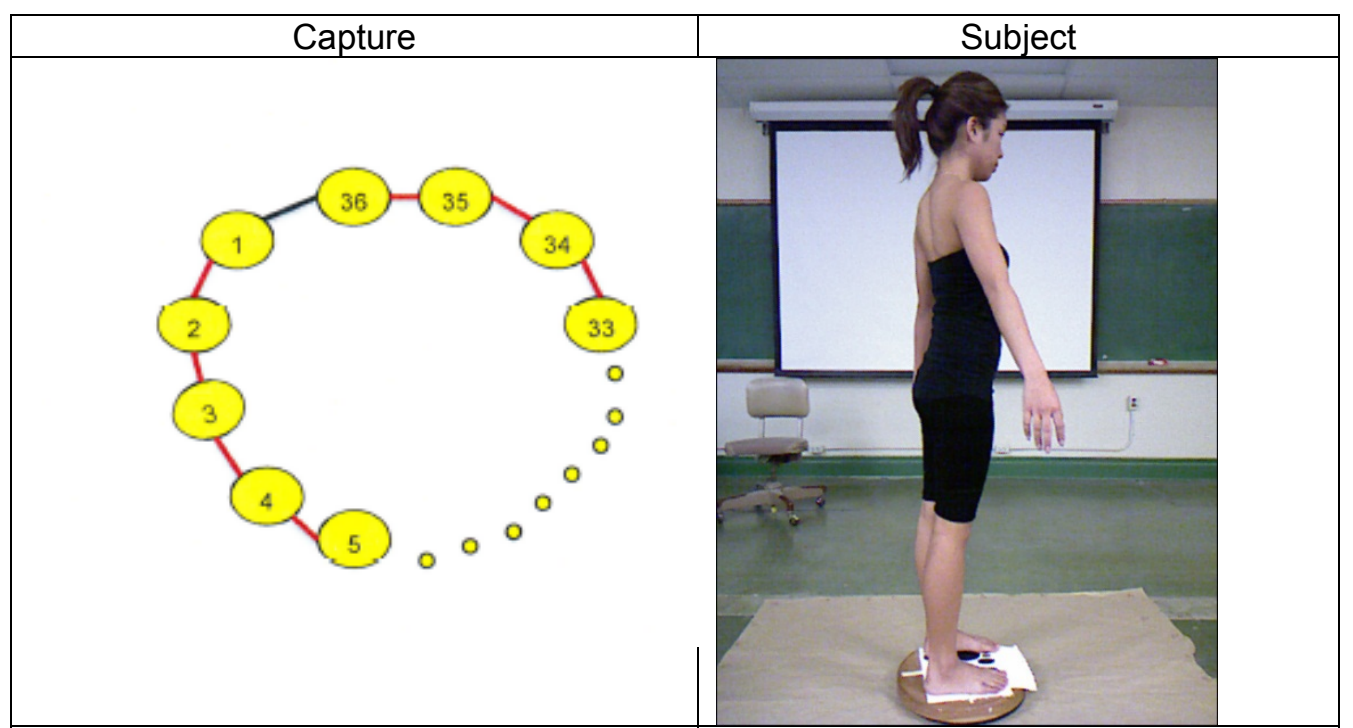

Fig. 1. Subject was captured from 360 degrees.

\subsection{Instrument}

Following body scanning and development of a digital avatar, subjects were asked to voluntarily respond to a 20 item questionnaire about their experience and satisfaction. The questionnaire was author developed and pretested. Questions were designed to gain background information about the subjects and an assessment of attitudes toward body scanning and satisfaction with digital avatars. 


\section{Test/Data}

\subsection{Digital Avatars}

Digital avatars (i.e., 3D model reconstruction) can be viewed with the program, MeshLab. Avatars can be observed from any angle and taken body measurement. For the color frames, the output is png file format, the depth is binary file format. Outputs with PNG and PLY files were abstracted from the scan data and processed into a 3D model reconstruction by Wissenschaftlicher Mitarbeiter.

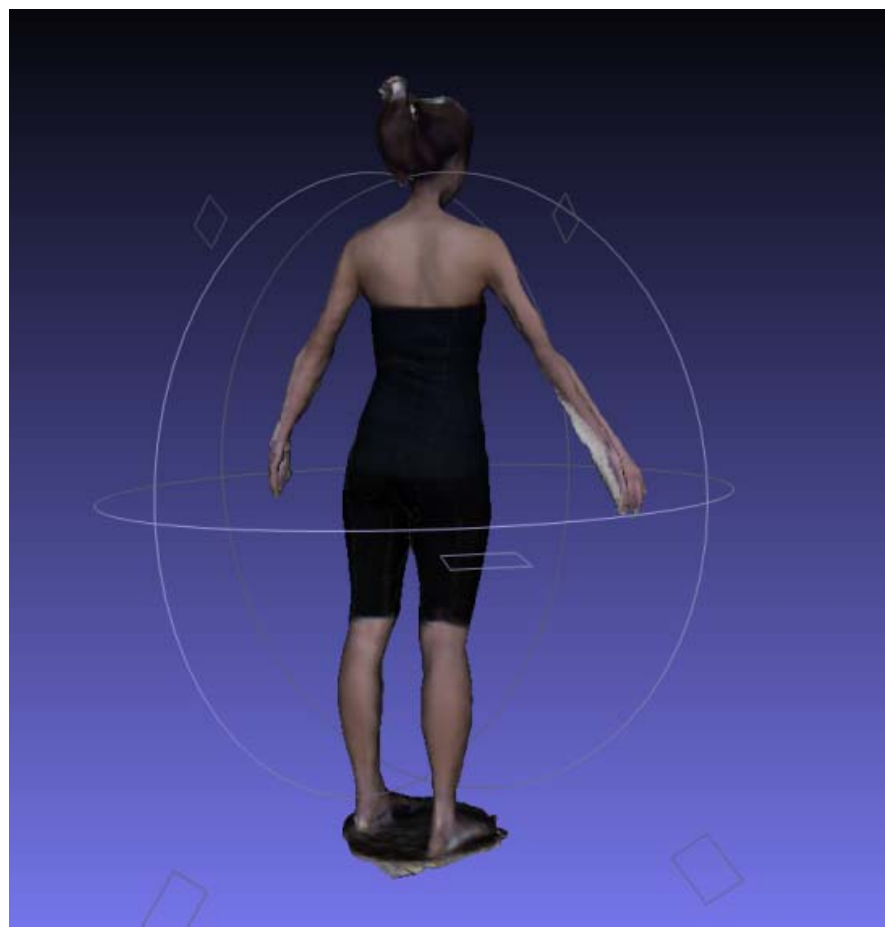

Fig. 1. Avatar viewed using MeshLab.

\section{Results}

\subsection{Responses Toward Avatars}

\subsubsection{Accurate Representation of Avatar}

Participants were asked the question "Do you find the 3-D body image avatar created by Kinect to be an accurate representation of your body?" The majority expressed their digital avatar was very accurate to moderately accurate. Table 1 . shows the accurate representation of 3-D body image avatar created by Kinect.

Table 1. Accurate Representation of Avatar Created by Using Body Image from Kinect.

\begin{tabular}{|l|l|l|}
\hline & $\begin{array}{l}\text { 3-D body image created } \\
\text { avatar by Kinect }\end{array}$ & Responses \\
\hline 1 & Very inaccurate & $14 \%$ \\
\hline 2 & Inaccurate & $6 \%$ \\
\hline 3 & Moderate & $34 \%$ \\
\hline 4 & Accurate & $31 \%$ \\
\hline 5 & Very accurate & $14 \%$ \\
\hline
\end{tabular}




\subsubsection{Satisfaction of Avatar}

The participants were asked the question "How satisfied are you with the 3-D body image created by Kinect captured data?" Approximately three quarters of participants expressed satisfaction with the avatar created using Kinect. Table 2. presents participants' satisfaction with the avatar from 3-D body image created by Kinect.

Table 2. Satisfaction of Avatar Created by Using Body Image from Kinect.

\begin{tabular}{|l|l|l|}
\hline & $\begin{array}{l}\text { 3-D body image created } \\
\text { avatar by Kinect }\end{array}$ & Responses \\
\hline 1 & Very dissatisfied & $14 \%$ \\
\hline 2 & Dissatisfied & $11 \%$ \\
\hline 3 & Moderate & $29 \%$ \\
\hline 4 & Satisfied & $43 \%$ \\
\hline 5 & Very satisfied & $3 \%$ \\
\hline
\end{tabular}

\subsection{Additional Results}

Results from the questionnaire included one male subject complained the current apparel sizing of using 3 variations of sleeve length and inseams did not fit all people. Also, the location of waist darts in some men's shirt resulted in a feminine look. One of subjects expressed the customized avatar could be used to make clothing for individual needs and one of a kind clothing. None of subjects previously experienced body scanning and creating their own avatar and expressed positive reactions to the new technology. Furthermore, less than $35 \%$ of the subjects have shopped for clothing on-line. About $15 \%$ of the subjects feel dissatisfied with parts of their body, such as the waist, feet, or hands. All subjects self-reported their own body type in good shape. Very few subjects will make special order clothing from their avatar; however, they believe strongly they will use this technology to select clothing. And about half of them will order clothing from a retailer store that would use their avatar.

\section{Conclusions}

Overall, the majority of participants expressed satisfaction with their 3-D body image. Additionally, the avatar was a moderate to very accurate representation of their bodies. Subjects also indicated positive responses about body scanning technology and future applications. College students can readily adopt the new equipment and technology because Kinect is very affordable and popular. It is believed Kinect will be used as a home based body scanning system to apply with any type of home shopping or on-line shopping. Also, this research provides valuable information about digital body imaging and avatars for various groups [8]. The body-scan project can apply to any age group and enable businesses to be on the cutting edge by responding to consumers in this new virtual world $[9,10,14]$. In future development, a set of nine-Kinect could reduce body scanning work time up to $89 \%$. Although more investment will be required, there will be a significant time saving and more accurate, efficient results. As 3-D body imaging becomes more affordable, efficient and practiced, it follows market applications will increase.

\section{References}

1. Suh, K., Kim, H., \& Suh, E.K. (2011). What if Your Avatar Looks Like You? Dual-Congruity Perspectives for Avatar Use. MIS Quarterly, 35(3), 711-729.

2. Istook, C.L., \& Hwang, S. (2001). 3D body scanning systems with application to the apparel industry . Journal of Fashion Marketing and Management. 5(2); 120-132.

3. Loker, S., Cowie, L., Ashdown, S., \& Lewis, V. D. (2004). Female Consumers' Reactions to Body Scanning, Clothing Textile \& Research Journal. 22(4), 151-160.

4. Lin, S., \& Mammel, K. (2011). An analysis of digital 3D body imaging technology. The $2^{\text {nd }}$ International Conference on 3D Body Scanning Technologies Proceedings, Lugano, Switzerland, 58-65. 
5. Aitpayev, K., \& Gaber, J. (2012). Creation of 3D human avatar using Kinect. Asian Transactions on Fundamentals of Electronics, Communication \& Multimedia, 1(05), 1-3.

6. Weiss, A., Hirshberg, D., \& Black, M.J. (2011). Home 3D body scans from noisy image and range data, International Conference on Computer Vision, ICCV, 1951-1958, Barcelona, Spain.

7. Sul, I.H., \& Kang, T.J. (2010). Regeneration of 3D body scan data using semi-implicit particle-based method. International Journal of Clothing Science and Technology, 22(4), 248-271.

8. Clarke, L., \& Korotchenko, A. (2011). Aging and the Body: A Review. Canadian Journal on Aging, 30(3), 495-510.

9. Brock, M.K., Ulrich, P.V., \& Connell, L.J. (2010). Exploring the apparel needs and preferences of tween girls and their Mothers. Clothing and Textiles Research Journal, 28(2), 95-111.

10. Honey, F., \& Olds, T. (2007). The standards Australia sizing system: quantifying the mismatch. Journal of Fashion Marketing and Management, 11(3), 320-331.

11. Cho, C., Park, J., Boeing, A., \& Hingston, P. (2010). An implementation of a garment-fitting simulation system using laser scanned 3D body data. Computers in Industry. 61(6), 550

12. Daanen, H., \& Hong, S. (2008). Made-to-measure pattern development based on 3D whole body scans. International Journal of Clothing Science and Technology, 20(1), 15-25.

13. Honey, F., \& Olds, T. (2007). The Standards Australia sizing system: quantifying the mismatch. Journal of Fashion Marketing and Management, 11(3), 320-331.

14. Loker, S., Ashdown, S., Cowie, L., Schoenfelder, K. (2004). Consumer interest in commercial application of body scan data. Journal of Textile and Apparel Technology and Management, 4(1), 1-13. 